\title{
Retrospective Study of Blood Transfusion Transmitted Infections (HIV, HCV, HBV, Syphilis \& Malaria] among the Blood Donors in Dhiraj Hospital
}

\author{
Jigna Patel ${ }^{1}$, Trupti Rajeshbhai Jansari ${ }^{2}$, Amit Chauhan ${ }^{3}$ \\ ${ }^{1}$ Assistant Professor, Department of Pathology, Smt BK Shah Medical Institute \& Research Centre, Sumandeep \\ Vidyapeeth an Institution Deemed to be University Piparia 391760 Vadodara Gujarat, ${ }^{2}$ Assistant Professor, \\ Department of Pathology, Smt BK Shah Medical Institute \& Research Centre, Sumandeep Vidyapeeth an Institution \\ Deemed to be University Piparia 391760 Vadodara Gujarat, ${ }^{3}$ Associate Professor, Department of Anesthesia, Smt \\ BK Shah Medical Institute \& Research Centre, Sumandeep Vidyapeeth an Institution Deemed to be University \\ Piparia 391760 Vadodara Gujarat.
}

\begin{abstract}
Abstret
A blood transfusion is a way of adding blood to your body after an illness or injury. It's a kind of life saving procedure. But this procedure also has life threatening hazards. Transfusion transmitted infections are one of the major side effects of blood transfusion. We can prevent them by proper screening of blood products and public awareness. To know about trend of transfusion transmitted infections (TTI) for the blood donors of Dhiraj hospital blood bank, the study was done.

Method: Study was done including blood donors of age 18-65 years from 2011 to 2016 retrospectively. TTIs testing for HIV, HBV and HCV was done with $3^{\text {rd }}$ generation ELISA but from the year 2016 onwards $4^{\text {th }}$ generation ELISA was used for HIV testing. Syphilis and malaria screening was done with rapid card test.

Result: Over a six year period total blood donation was 20,392. The overall prevalence of HIV, HbsAg, $\mathrm{HCV}$, syphilis and malaria were $0.16 \%, 1.43 \%, 0.10 \%, 0.61 \%$ and $0.009 \%$ respectively.

Conclusion: Nucleic acid amplification testing (NAT) must be applied that identify positive blood donor during the immunological window period before seroconversion. Information to TTIs reactive donor is a best method to prevent the chance of repeated reactive donation.
\end{abstract}

Keywords: Blood donor, ELISA, NAT, Seroprevalance, TTI.

\section{Introduction}

Blood is a special form of natural fluid that is made $\&$ synthesized within the body and again used by the

\section{Corresponding Author:}

\section{Dr. Trupti Jansari}

Assistant Professor, Department of Pathology, Smt BK Shah Medical Institute \& Research Centre, Sumandeep Vidyapeeth an institution deemed to be University Piparia 391760 Vadodara Gujarat e-mail: creativity.art.j@gmail.com Postal Address: 11 Gopi-vallabh soc, near amin party plot, H.T. road, gotri, Vadodara, Gujarat, 390023

Phone No.: 9727079195 body for different bodily function. Despite all the medical advances, there is no good manmade substitute for human blood, which is why blood transfusion is still clinically important for human being. Blood transfusion means transferring blood or blood base products from the donor into the circulatory system of recipient. Blood transfusion is unique technology in which its collection, processing and use are scientifically based. But its availability depends on the extraordinary generosity of the people who donate it. ${ }^{[1]}$

Blood banks are essential part of each and every hospital with basic purpose of provision of blood transfusion services. Blood transfusion services are required in a number of clinical conditions like 
anemia, thalasemia, hemophilia or may be required in gynecological problems or when surgery of the patient is unavoidable. Transfusion of blood/blood product becomes unavoidable if there is extensive bleeding during surgery. ${ }^{[2]}$

Large number of people are exposed to life threateing risks of TTIs such as Hepatitis B, Hepatitis $\mathrm{C}$, Malaria, Autoimmune deficiency virus infection and Syphilis due to tansfusion of unsafe blood which can be avoidable. There is a challenge for safe transfusion, requiring the application of science \& technology to blood processing \& testing. ${ }^{[1]}$

The present study gives the idea about the current situation of transfusion transmission related infections and that will help in the way to establish a good national strategy for the blood donation system.

\section{Materials and Method}

The present study was carried out using a retrospective blood donor related data from january 2011 to december 2016 in Dhiraj blood bank unit of Dhiraj hospital.

Inclusion: Every single blood donor who came to Dhiraj Hospital from january 2011 to december 2016 who satisfied the criteria for blood donation as per drugs and cosmetic act 1940 were included.

Exclusion: Blood donor not satisfying the criteria for blood donation as per drugs and cosmetic act 1940 .

The donor questionnaire forms with details of donors like demographic data, age, weight, hemoglobin status and the results of serological test are recorded and maintained in blood bank of Dhiraj Hospital. We saw the data and there were approximate 20,392 donors who donated blood in last 6 years.

From all related data records, we collected data of blood donors without revealing their personal identity.

Here in Dhiraj Hospital blood bank, firstly Blood Donors comes to Blood bank and their counselling is done by social worker. The venous blood is collected from all eligible donors with their permission after the complete physical examination by Blood bank medical officer. For screening, venous blood is collected in plain vaccute, it is allowed to clot naturally and serum is seperated after centrifugation. Serum sample is then subjected to serological tests for $\mathrm{HBV}, \mathrm{HCV}$, HIV, syphilis and malaria infection screening.

Two kits are used based on WHO recommendation for two different testing strategies involved in ELISA and simple or rapid essays for surveillance. In house positive and negative controls are performed for each serological test.

*HIV screening is done using Erba Lisa $3^{\text {rd }}$ generation and Erba Lisa HIV generation 4 from the year 2016 onwards.(ELISA)

*HBS screening is done using Erba Lisa HBV generation 3. (ELISA)

* HCV screening is done using Erba Lisa HCV generation 3. (ELISA)

*Malarial parasite screening is done using pan/pf malaria rapid card.

*Syphilis screening is done using VDRL rapid card.

Patients suffering from any of infections are referred for the necessary treatment.

Collected data was compiled in Microsoft office Excel 2013 format. Data was presented in tabulated format. Descriptive method was used for the preparation of result.

\section{Result}

We evaluated a total of 20392 units of blood during $1^{\text {st }}$ January 2011 to $31^{\text {st }}$ December 2016 . The result was interpreted and following details were drawn in a table.

Table 1: Blood collection during study period

\begin{tabular}{|c|c|}
\hline Study Years & Unit Collection \\
\hline 2011 & 2484 \\
\hline 2012 & 2732 \\
\hline 2013 & 3086 \\
\hline 2014 & 3140 \\
\hline 2015 & 4037 \\
\hline 2016 & 4913 \\
\hline Total collection & $\mathbf{2 0 3 9 2}$ \\
\hline
\end{tabular}

Table showing the year wise collection of blood units, year 2011 show the lowest collection (2484), and the highest collection was found in 2016(4913). The number of donations has increased from 2484 in 2011 to 4913 in 2016. 
Table 2: Distribution of voluntary and replacement donor

\begin{tabular}{|c|c|c|c|c|c|c|c|}
\hline \multirow{2}{*}{ Year } & \multicolumn{3}{|c|}{ Voluntary Donor } & \multicolumn{3}{|c|}{ Replacement Donor } & \multirow{2}{*}{ Grand Total } \\
\hline & $\mathbf{M}$ & $\mathbf{F}$ & Total & M & $\mathbf{F}$ & Total & \\
\hline 2011 & 495 & 35 & 530 & 1949 & 5 & 1954 & 2484 \\
\hline 2012 & 794 & 65 & 854 & 1855 & 23 & 1878 & 2732 \\
\hline 2013 & 442 & 75 & 517 & 2541 & 28 & 2569 & 3086 \\
\hline 2014 & 484 & 104 & 588 & 2522 & 30 & 2552 & 3140 \\
\hline 2015 & 241 & 85 & 326 & 3688 & 23 & 3711 & 4037 \\
\hline 2016 & 322 & 50 & 372 & 4513 & 28 & 4541 & 4913 \\
\hline Total & 2778 & 414 & 3187 & 17068 & 137 & 17205 & 20392 \\
\hline
\end{tabular}

During the study period, $17205(84.37 \%)$ of the donors were replacement donors and remaining $3187(15.62 \%)$ were voluntary. The heighest voluntary donation trend of 854(26.79\%) donors was seen in 2012. In six year study overall voluntary blood donation has decreased and replacement blood donation has increased.

Table shows 19,846 (97.32\%) were males blood donors and $551(2.7 \%)$ were females blood donors giving male: female ratio of $36: 1$.

Seropositivity distribution in the study with an average prevalence of $2.32 \%$ showed higher prevalence in the years 2013 (2.91\%), 2012 (2.56\%), 2015 (2.47\%) and $2011(2.41 \%)$. Lower prevalence was seen in the years 2016(1.99\%) and 2014(1.81\%).
Table 3: Seropositive and seronegative blood samples from the year 2011 to 2016

\begin{tabular}{|c|c|c|c|}
\hline Year & Positive & Negative & Total \\
\hline \multirow{2}{*}{2011} & 60 & 2424 & \multirow{2}{*}{2484} \\
\hline & $2.41 \%$ & $97.58 \%$ & \\
\hline \multirow{2}{*}{2012} & 70 & 2662 & \multirow{2}{*}{2732} \\
\hline & $2.56 \%$ & $97.43 \%$ & \\
\hline \multirow{2}{*}{2013} & 90 & 2996 & \multirow{2}{*}{3086} \\
\hline & $2.91 \%$ & $97.08 \%$ & \\
\hline \multirow{2}{*}{2014} & 57 & 3083 & \multirow{2}{*}{3140} \\
\hline & $1.81 \%$ & $98.18 \%$ & \\
\hline \multirow{2}{*}{2015} & 100 & 3937 & \multirow{2}{*}{4037} \\
\hline & $2.47 \%$ & $97.52 \%$ & \\
\hline \multirow{2}{*}{2016} & 98 & 4815 & \multirow{2}{*}{4913} \\
\hline & $1.99 \%$ & $98.00 \%$ & \\
\hline
\end{tabular}

Table 4 : Overall prevalence of TTIs among blood donors

\begin{tabular}{|c|c|c|c|c|c|c|}
\hline \multirow{2}{*}{ Year } & \multicolumn{9}{|c|}{ Test Positive } \\
\cline { 2 - 7 } & HIV & HCV & HBsAg & VDRL & Malaria & Total \\
\hline 2011 & $6(10 \%)$ & $1(1.66 \%)$ & $39(65 \%)$ & $14(23.33 \%)$ & $00(00 \%)$ & $60(2.41 \%)$ \\
\hline 2012 & $3(4.28 \%)$ & $7(10 \%)$ & $44(62.85 \%)$ & $16(22.85 \%)$ & $00(00 \%)$ & $70(2.56 \%)$ \\
\hline 2013 & $6(6.66 \%)$ & $7(7.77 \%)$ & $51(56.66 \%)$ & $27(30 \%)$ & $00(00 \%)$ & $90(2.91 \%)$ \\
\hline 2014 & $3(5.26 \%)$ & $2(3.5 \%)$ & $33(57.89 \%)$ & $19(33.33 \%)$ & $00(00 \%)$ & $57(1.81 \%)$ \\
\hline 2015 & $4(4 \%)$ & $4(4 \%)$ & $59(59 \%)$ & $31(31 \%)$ & $02(2 \%)$ & $100(2.47 \%)$ \\
\hline 2016 & $12(12.24 \%)$ & $0(0 \%)$ & $67(68.36 \%)$ & $19(19.38 \%)$ & $00(00 \%)$ & $98(1.99 \%)$ \\
\hline Total & $\mathbf{3 4 ( 0 . 1 6 \% )}$ & $\mathbf{2 1 ( 0 . 1 0 \% )}$ & $\mathbf{2 9 3}(\mathbf{1 . 4 3 \%})$ & $\mathbf{1 2 6 ( 0 . 6 1 \% )}$ & $\mathbf{0 2}(\mathbf{0 . 0 0 9} \%)$ & $\mathbf{4 7 5}(\mathbf{2 . 3 2} \%)$ \\
\hline
\end{tabular}

The rate of all five mandatory TTI markers were $2.32 \%$. The prevalence was found for individual TTI markers and arranged in decreasing order: HBV, Syphilis,
HIV, HCV, Malaria were respectively $1.43 \%, 0.61 \%$, $0.16 \%, 0.10 \%, 0.009 \%$. 
Table 5: Dual infections among donors

\begin{tabular}{|l|c|}
\hline Type of infection & No. of Positive \\
\hline HBV and HCV & 1 \\
\hline HCV and VDRL & 1 \\
\hline HBV and HIV & 1 \\
\hline HBV and VDRL & 2 \\
\hline
\end{tabular}

As shown in table during the study period five donors showed co-infectio

\section{Discussion}

Though the blood transfusion plays a vital role in management of many diseases, it always carries a risk of TTIs and many other adverse reactions. Blood transfusion is a highly avoidable treatment ever prescribed. It is essential to adopt strict criteria in selection of donors and to avoid unnecessary transfusion bacause there is no screening method which can make transfusion transmitted disease rate at zero level. ${ }^{[3]}$

During the study period, the rate of all five mandatory TTI markers were $2.32 \%$. Amrutha Kumari $\mathrm{B}$ et al ${ }^{[4]}(2.81 \%)$ also found similar to lower transfusion transmitted infections marker rates and for other studies comparison see table no. 6 .

Among all TTI markers, highest prevalance was for HBV $(1.43 \%)$ in present study, but its prevalance was low when we compare it with $\operatorname{Karnataka}(1.77 \%)^{[4]}$ and Bengaluru $(1.86 \%)^{[5]}$ studies. Frequency of occuring hepatitis infection after blood transfusion is higher than any other infection. HBV was the most prevalent TTI in blood donors, suggesting that it might be linked with poor health practice of people, high cost of good health facilities and economic status. Ensuring good health facilities at low cost by Government may reduce the risk factor of these common infectious diseases and ensure better health conditions. Economic status also plays a very important role. Consultancy with health specialist during early diseases may reduce the prevalence of infectious diseases. ${ }^{[2,6]}$

$\mathrm{HCV}$ infection is about $1 \%$ according to the national center for disease control in India. In this study its about
$0.10 \%$. As shown in table -6 , majority of the blood donors studied from different regions of India have higher prevalence rate as compare to this study. ${ }^{[7,8,9]}$

Syphilis is sexually transmitted disease so when someone diagnosed with it, it means individuals maybe exposed to other sexually transmitted disease also. So screening of donated blood for syphilis is important. Thus it serves primarily as a surrogate test to identify donors with potentially high risk behavior. Our study showed that the prevalence of syphilis was $0.61 \%$. Prevalence of syphilis is higher among male that might be related to common bedding in working place and no proper cleanliness. ${ }^{[2,8,10]}$

The HIV/AIDS pandemic has focused particularly on the importance of preventing transfusion-transmit ted infections. Up to $3 \%$ of HIV infections worldwide are transmitted through the transfusion of contaminated blood and blood products. ${ }^{[11]}$ In present study, six years sero-reactivity rate was $0.16 \%$.

The fifth and mandatory but neglected marker for TTI screening in India is Malaria. In our study malaria prevalence rate was $0.009 \%$. Its low because of better pre donation screening and people knows well about the symptoms of malaria.

Most blood banks in India use ELISA kit which cannot detect HIV before 22 days, HBV before 59 days and HCV before 82 days of infection. Usually when we do the blood transfusion, volume which is given is very large so even lowest viral load cause transmission of infection. Prevalence of asymptomatic carriers in the society, and when the blood donations done in window period of infections which also posses a great threat to safe blood supply.

The most effective strategy must be started where we inform the TTI positive donors and advice them for no such donation in future. They should be sent for appropriate treatment. Pre-donation counseling and donor self-exclusion will be effective in decreasing the TTIs as well as practices of autologus blood transfusion should be encouraged. 
Table 6: Comparision of Tansfusion transmitted infection markers in different studies.

\begin{tabular}{|c|c|c|c|c|c|c|c|}
\hline \multirow{2}{*}{ Studies } & \multirow{2}{*}{$\begin{array}{l}\text { Region of } \\
\text { study }\end{array}$} & \multirow{2}{*}{$\begin{array}{l}\text { Period of } \\
\text { Study }\end{array}$} & \multicolumn{5}{|c|}{ TTIs markers prevalence rate } \\
\hline & & & HBV & $\mathrm{HCV}$ & HIV & Syphilis & Malaria \\
\hline Leena MS et al[12] & South India & 2004 to 2010 & 0.7 & 0.1 & 0.2 & 0.1 & 0.13 \\
\hline Amrutha Kumari B et al ${ }^{[4]}$ & Karnataka & 2006 to 2010 & 1.7 & 0.1 & 0.6 & 0.2 & \\
\hline Kumar $\mathrm{R}$ et $\mathrm{al}^{[6]}$ & Punjab & 2008 to 2013 & 1.0 & 1.5 & 0.2 & 1.7 & 0.006 \\
\hline Panda $\mathrm{M}$ et al ${ }^{[13]}$ & Orissa & 2005 & 1.1 & 1.9 & $0 . .3$ & & \\
\hline Srikrishna A et al ${ }^{[7]}$ & Bengaluru & 1997 to 1998 & 1.8 & 1.0 & 0.4 & 1.6 & \\
\hline Sastry JM et al ${ }^{[14]}$ & Pune & 2008 to 2013 & 1.2 & 0.4 & 0.2 & 0.008 & \\
\hline Present Study & Vadodara & 2011 to 2016 & 1.4 & 0.10 & 0.1 & 0.6 & 0.009 \\
\hline
\end{tabular}

\section{Conclusion}

The present study has limitations in the use of ELISA test for TTIs screening. The latest more sensitive method such as PCR(Polymerase chain Reaction) and NAT (Nucleic acid amplification Test) can uncover latent infections in the window period and may actually suggest underestimation of prevalence by currently used screening tests in the present study. This implies that screening for TTI needs to be upgraded across blood banks in India. HBV was the most prevalent TTI among all, so there is a need of initiating efforts for community level health program for HBV in addition to UIP (Universal Immunisation Programme] with HBV vaccine started in 2007 and the government should focus on present youth population which has not taken this vaccine in childhood life.

Ethical Clearance: Ethical clearance was taken from SBKS \& MIRC

\section{Source of Funding: Self}

\section{Conflict of Interest: Nil}

\section{References}

1. Shirin T, Tahmeed A, Anwarul I, Munirul I and Nazrul I. 2000. Prevalence and risk factors of hepatitis $B$ virus, hepatitis $C$ virus and HIV infection among drug addicts in Bangladesh. J. Health Popul. Nutr. 18(3]: 145-150.

2. Sawke N, Sawke GK, Chawla S Seroprevalence of common transfusion transmitted infections among blood donors. People's J Sci Res, 2010:30:5-7.

3. Afsar I, Gungor S, Sener AG, Yurtsever SG. The prevalence of $\mathrm{HBV}, \mathrm{HCV}$ and $\mathrm{HIV}$ infections among blood donors in Izmir, Turkey. Indian J Med Microbiol. 2008;26:288-9.

4. Amrutha Kumari B, Deepa S, Venkatesha D. Blood Transfusions: Are They Life Saving or Transfusing Infections? Online J Health Allied Scs. 2011;10(2]:7.

5. Kotwal U, Doda V, Arora S, Bhardwaj S. Blood donor notification and counseling: Our experience from a tertiary care hospital in India. Asian $\mathbf{J}$ TransfusSci. 2015;9:18-22.

6. Kumar R, Gupta S, Kaur A, Jindal A, Sharma H. Sero-prevalence and changing trends of transfusion transmitted infections among blood donors in a tertiary care hospital. Indian J Comm Health. 2015;27(1]: 25-9.

7. Srikrishna A, Sitalakshmi S, Damodar P. How safe are our safe donors? Indian J. Pathol Microbiol. 1999;42:411-6.

8. Ujjan ID, Memon RA, Butt AR, etal. Seroprevalence of HbsAg and anti-HCV in healthy blood Donors. Pak J Gastroenterol, 2006;20(1]:75-7.

9. Shrivastava A, Kumar S. Hepatitis in India: Burden, Strategies and Plans. NCDC Newsletter [Internet]. 2014;3(1]:2-3. Available from: http:// www.ncdc.gov.in/writereaddata/linkimages/ NewsLtr0103_20146480274026.pdf

10. Singh K, Bhat S, Shastry S. Trend in Seroprevalence of Hepatitis B Virus Infection among Blood Donors of Coastal Karnataka, India. J Infect Dev Ctries. 2009;3(5]:376-9.

11. Khare V, Jain VK, Tantuway R. Study of Transfusion transmittable Infections: Seroprevalence among Blood Donors in a tertiary Care Hospital of 
central India. Biomed Rev: J Basic Appl Med Sci. 2014;1(1]:17-21.

12. Leena MS, Mohd. Shafee. Trend and prevalence of transfusion transmitted infections among blood donors in rural teaching institute, south India. Journal of Pathology of Nepal. 2012;2:203-6.

13. Panda M, Kar K. HIV, hepatitis B and C infection status of the blood donors in a blood bank of a tertiary health care centre of Orissa. Indian J Public Health. 2008;52:43-4.

14. Sastry JM, Agawane SU, Harke VA. Retrospective study of the five-Year Prevalence and Trends of transfusion transmitted infections (TTIs] among blood donors at a charitable hospital blood bank in Pune, India. International J. of Healthcare and Biomedical Research. 2014;2(3]:193-200. 